\title{
Lower energy radial shock wave therapy improves characteristics of hypertrophic scar in a rabbit ear model
}

\author{
JING-CHUN ZHAO, BO-RU ZHANG, KAI SHI, JIAN WANG, QING-HUA YU and JIA-AO YU \\ Burns and Plastic Reconstruction Unit, The First Hospital of Jilin University, Changchun, Jilin 130021, P.R. China
}

Received June 28, 2017; Accepted November 2, 2017

DOI: 10.3892/etm.2017.5441

\begin{abstract}
The aim of the present study was to investigate the effects of radial extracorporeal shock wave therapy (rESWT) on scar characteristics and transforming growth factor (TGF)- $\beta 1 /$ Smad signaling in order to explore a potential modality for the treatment of hypertrophic scars (HS). The HS model was generated in rabbit ears, then rabbits were randomly divided into 3 groups: Lower(L)-ESWT [treated with rESWT with lower energy flux density (EFD) of $0.1 \mathrm{~mJ} / \mathrm{mm}^{2}$ ], higher (H)-ESWT (treated with a higher EFD of $0.18 \mathrm{~mJ} / \mathrm{mm}^{2}$ ) and the sham ESWT group (S-ESWT; no ESWT treatment). Scar characteristics (wrinkles, texture, diameter, area, volume of elevation, hemoglobin and melanin) were assessed using the Antera 3D ${ }^{\circledR}$ system. The protein and mRNA expression of TGF- $\beta 1, \mathrm{Smad} 2, \mathrm{Smad} 3$ and Smad7 was assessed by enzyme-linked immunosorbent assay and reverse transcription-quantitative polymerase chain reaction, respectively. The Antera $3 \mathrm{D}^{\circledR}$ results indicated that wrinkles and hemoglobin of the HS were significantly improved in both of the rESWT groups when compared with the S-ESWT group. However, these changes appeared much earlier in the L-ESWT group than the H-ESWT. Scar texture was also improved in the L-ESWT group. However, rESWT did not influence HS diameter, area, volume of elevation or melanin levels. rESWT had no effect on TGF- $\beta 1$ or Smad7 expression in either of rESWT groups. Although no difference was observed in Smad2 mRNA expression in the L-ESWT group, the Smad 3 mRNA and protein expression significantly decreased when compared with the H-ESWT and S-ESWT groups. By contrast, Smad2 and Smad3 mRNA expression were upregulated in the H-ESWT group. These results demonstrated that $\mathrm{rESWT}$ with $0.1 \mathrm{~mJ} / \mathrm{mm}^{2} \mathrm{EFD}$ improved some characteristics of the HS tissue. Downregulation of Smad3 expression may underlie this inhibitory effect. Inhibition of the TGF- $\beta 1 /$ Smad signal transduction pathway may be a potential therapeutic target for the management of HS.
\end{abstract}

Correspondence to: $\mathrm{Dr}$ Jia-Ao Yu, Burns and Plastic Reconstruction Unit, The First Hospital of Jilin University, 71 Xinmin Street, Changchun, Jilin 130021, P.R. China

E-mail: bu_dong007@163.com

Key words: extracorporeal shock wave therapy, hypertrophic scar, transforming growth factor- $\beta 1 /$ Smad signaling, Smad3

\section{Introduction}

Hypertrophic scar (HS) formation is a common sequel to injuries, burns and surgical operations. Up to $40-70 \%$ of all surgical patients, and up to $91 \%$ of all burn patients are may be affected by HS formation (1). Hypertrophic scar has a detrimental effect on the patient's physical as well as psychological health. The effects may include, pain, itching, functional impairment, disfigurement, anxiety, depression, and poor quality of life of the affected person (2). Treatment of HS is typically challenging; further research is required to devise appropriate interventions.

The precise pathogenetic mechanism underlying HS formation is not clearly understood1. However, it is known to result from excessive post-traumatic regeneration of tissue, abnormal extracellular matrix (ECM) deposition and collagen remodeling (3). The pathophysiological basis of HS formation involves interaction between a diverse range of microcellular actors and processes. These include abnormal activation, proliferation, synthesis, and differentiation and secretions of connective tissue (such as fibroblasts, myofibroblasts and keratinocytes), growth factors and cytokines. This in turn leads to abnormal collagen synthesis and HS formation via dysregulation of certain cellular signaling pathways, such as TGF- $\beta 1 /$ Smad pathway (Fig. 1). In addition, other signaling pathways, such as mitogen-activated protein kinase, extracellular signal-regulated kinase and c-Jun N-terminal kinase pathway, have also been implicated along with TGF- $\beta$ signaling. However, the exact mechanisms are not yet clear (4-7).

The goal of managing HS is symptom alleviation, functional restoration and recurrence prevention. Currently practiced therapeutic modalities for treatment of HS include, topical and systemic medication (8), surgery, physical treatment (e.g., laser and particle beams, compression therapy and massage, etc (9-11), silicone gel or sheeting (12), radiotherapy (13), cryotherapy (14), and mesenchymal or adipose derived stem cell therapy (15). All these therapeutic modalities have their inherent limitations and advantages; there is no single universally accepted gold standard therapy for HS (16). For example, the disadvantages of intralesional injection treatment include invasion, pain, pigmentation changes, ulceration, blister formation, and necrosis (17). Compression therapy for HS is liable to induce severe discomfort, limitation in movement because of pressure effect, ulceration, blister formation, itching and rashes (18). Hypopigmentation and the potential for carcinogenesis are 
some of the concerns associated with the use of cryotherapy (19) and radiotherapy (20), respectively. Therefore, developing a non-invasive, safe, efficacious and cost-effective treatment modality for HS will be of immense benefit.

Extracorporeal shock wave therapy (ESWT) is a type of pulsed acoustic wave resulting from dramatic changes in pressure. ESWT was originally used for urinary lithotripsy (21). Of late, its application has been extended to other areas including treatment of fracture nonunion, musculoskeletal disorders and soft tissue wounds (22-24). Radial ESWT, also referred as unfocused ESWT, is generally divided into two categories based on the energy flux density (EFD) applied, i.e., higher EFD rESWT and lower EFD rESWT. However, there is a lack of consensus on the validity of this classification. Speed et al (25) recommended a threshold level of $0.12 \mathrm{~mJ} / \mathrm{mm}^{2}$ for differentiating between higher EFD and lower EFD rESWT, while Goertz et al suggested a threshold level of $0.15 \mathrm{~mJ} / \mathrm{mm}^{2}$ (26). Radial ESWT is known to alleviate tissue ischemia, heal burn wounds and diabetic foot ulcers, improve uptake of skin grafts, and has the advantage of being non-invasive, safe and convenient to use $(27,28)$. Radial ESWT is known to promote angiogenesis, inhibit local inflammation, promote recruitment of mesenchymal stem cells and endothelial progenitor cells at the injured site, stimulate cellular proliferation, regeneration, and decrease bacterial colonization (29).

Despite its advantages, the use of rESWT in the treatment of HS has not been adequately investigated. Fioramonti et al (30) documented satisfactory results, in terms of texture and color improvement, from use of ESWT in 16 patients with post-burn scars. Cho et al (31) report that ESWT significantly reduced scar pain in burn patients after wound recovery. Similarly, Saggini et al (32) evaluated the efficacy of unfocused shock wave treatment on retracting scars of the hands. They observed significant early improvement in modified Vancouver Scar Scale after treatment. Comparable results were obtained with respect to pain and range of movements. However, few studies were able to elucidate the underlying mechanism of action. Histologic changes in connective tissue appearance, scar vascularization and density of fXIIIa and CD34-positive cells were found following ESWT treatment (32).

In the present study, we investigated whether rESWT can serve as an effective modality for improving characteristics of hypertrophic scar by interfering with the TGF- $\beta 1 / \mathrm{Smad}$ signaling pathway.

\section{Materials and methods}

Ethical approval. The study protocol was approved by the Institutional Ethics Committee at The First hospital of Jilin University.

Establishment of rabbit ear HS model. Twenty five adult white rabbits (male: female ratio, 13: 12, weight: $2.0-2.3 \mathrm{~kg}$ each) were obtained from the Laboratory Animal Center of Jilin University. The rabbits were acclimatized and housed separately at $22-25^{\circ} \mathrm{C}$ with $60-70 \%$ humidity, in a 12 -h light/dark cycle for $48 \mathrm{~h}$. The HS model was established as described by Morris et al (33). In brief, the rabbits were anesthetized with intravenous ketamine $(30 \mathrm{mg} / \mathrm{kg})$ injection into auricular vein. Four full thickness circular wounds (15 mm diameter) were inflicted on the ventral surface of each ear with a scalpel, avoiding damage to the visible vessels. The separation between each wound was $>15 \mathrm{~mm}$. The epidermis, dermis, and perichondrium were carefully stripped. The full-thickness wounds with exposed cartilage were covered with erythromycin eye ointment. Post anesthesia, the rabbits were placed in their previous cages. Secretions and exudates were gently removed on the following day. No topical wound care was provided and the wounds were left to heal spontaneously. Hypertrophic scars were formed three weeks after the surgery and histopathological examination was performed (Fig. 2).

ESWT treatment protocol. Three weeks after HS model establishment, twenty four rabbits (one was already used for HS testing) were randomly allocated to three groups: $\mathrm{rESWT}$ with lower EFD of $0.1 \mathrm{~mJ} / \mathrm{mm}^{2}$ (L-ESWT), $\mathrm{rESWT}$ with higher EFD of $0.18 \mathrm{~mJ} / \mathrm{mm}^{2}$ (H-ESWT) and sham ESWT treatment group (S-ESWT). The Swiss DolorClast ${ }^{\circledR}$ Classic (EMS Electro Medical Systems, Nyon, Switzerland) convex 15-mm shock wave applicator was gently placed on the HS surface which was covered with a liberal amount of medical ultrasound coupling agent as a conductive gel. In the L-ESWT and H-ESWT groups, a single shock wave treatment with 500 impulses at a frequency of $8 \mathrm{~Hz}$ was administered once a week for four weeks $\left(0.1 \mathrm{~mJ} / \mathrm{mm}^{2}\right.$ for L-ESWT and $0.18 \mathrm{~mJ} / \mathrm{mm}^{2}$ for H-ESWT, respectively) (Fig. 3). S-ESWT group also received identical treatment; however, no shock wave impulse was administered. Rabbits appeared to tolerate the rESWT treatment well without anesthetic cover.

Samples and data collection. The characteristics of HS were assessed using Antera 3D ${ }^{\circledR}$ (v2.0; Miravex Limited, Dublin 2, Dublin, Ireland), with the camera held in tight apposition to the wound and the push button on the camera clicked to obtain a higher resolution image. The image was saved and the characteristics were measured in terms of the presence of wrinkles, texture, volume of elevation $\left(\mathrm{mm}^{3}\right)$, area $\left(\mathrm{mm}^{2}\right)$, diameter $(\mathrm{mm})$, melanin and hemoglobin of scar using the mode selection menu ( $2 \mathrm{~mm}$ filter was used for wrinkles, texture and elevations) (Fig. 4). Findings were assessed with Antera $3 \mathrm{D}^{\circledR}$ on days $1,4,7,10,14,21,28$ and 35 of initial rESWT treatment.

A separate set of fresh tissue samples were harvested for determining gene and protein expression under intravenous anesthesia, as described above, on days 1, 4, 7, 10, 14, 21, 28 and 35 of the initial rESWT treatment. One wound per rabbit and time point for taking samples. Prior to their processing, all specimens were snap-frozen in liquid nitrogen.

Reverse transcription- polymerase chain reaction (RT-PCR). Hypertrophic scar tissues were homogenized using an electronic high-speed homogenizer. Total RNA was obtained using TRIzol ${ }^{\circledR}$ Reagent (Invitrogen Life Technologies, Carlsbad, CA, USA) according to the manufacturer's instructions. The total RNA concentration in each HS sample was determined with Epoch ${ }^{\mathrm{TM}}$ Multi-Volum Microplate Spectrophotometer System (BioTek Instruments, Inc., Winooski, VT, USA). After reverse transcription with M-MLV Reverse Transcriptase (Promega Corp., Madison, WI, USA) using Oligo (dT)15 Primer 


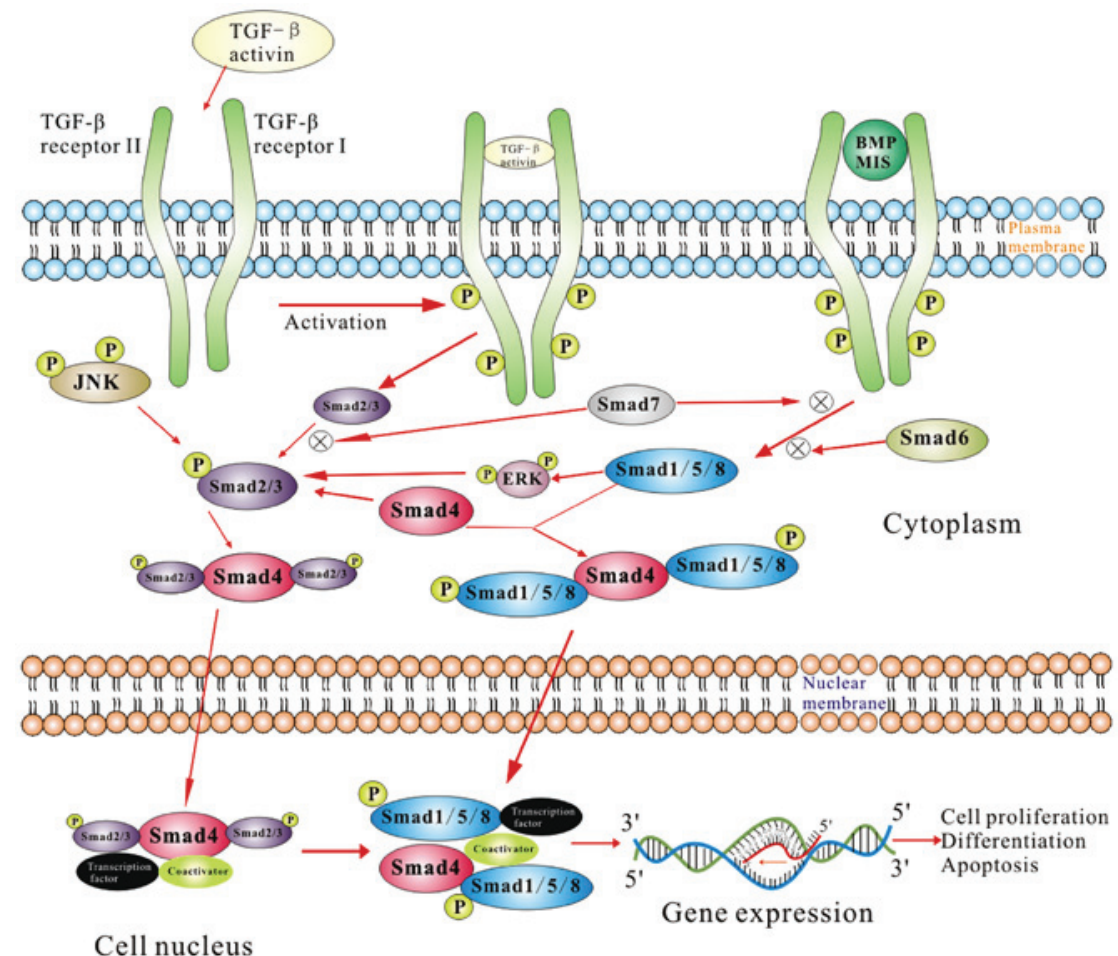

Figure 1. Schematic illustration of the transforming growth factor- $\beta 1 /$ Smad signaling pathway.
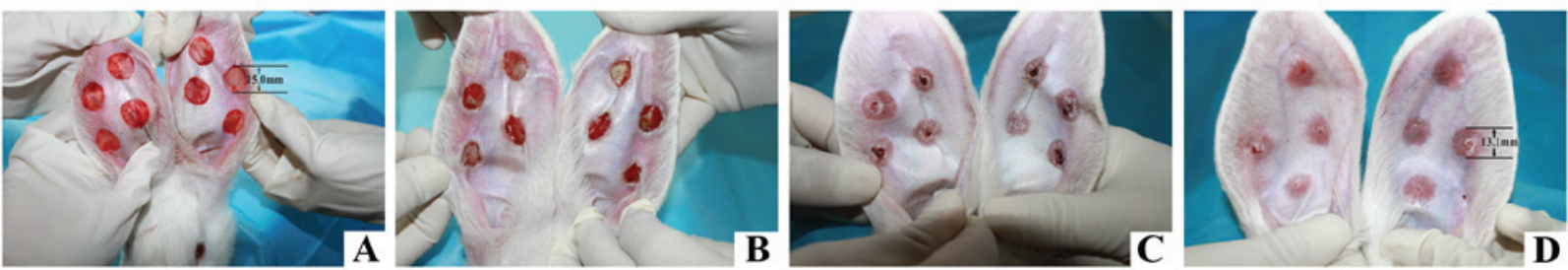

Figure 2. Post-treatment photographs of HS model in rabbit ear. Images were taken of the hypertrophic scars created, (A) immediately following surgery, (B) 1 week following the induction of the HS model, (C) 2 weeks following the induction of the HS model and (D) 3 weeks following the induction of the HS model. HS, hypertrophic scar.

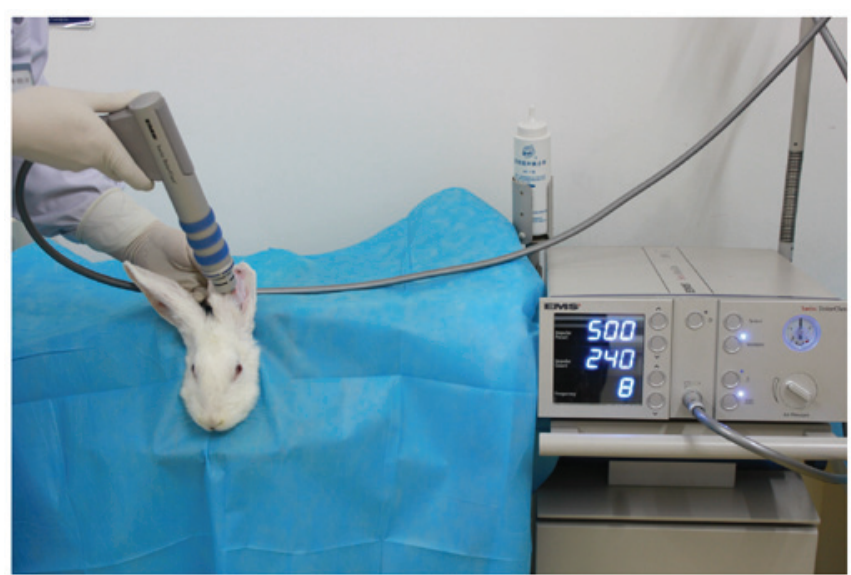

Figure 3. Treatment of the hypertrophic scars on rabbit ears using radial extracorporeal shock wave therapy.

(Promega) for $75 \mathrm{~min}\left(37^{\circ} \mathrm{C}\right.$ for $5 \mathrm{~min}, 42^{\circ} \mathrm{C}$ for $60 \mathrm{~min}$, and $95^{\circ} \mathrm{C}$ for $10 \mathrm{~min}$ ), $2 \mu \mathrm{l}$ first strand cDNA template was amplified by polymerase chain reaction (PCR) with $25 \mu \mathrm{l} \mathrm{GoTaq}{ }^{\circledR}$ Green
Master Mix (Promega), $19 \mu \mathrm{l}$ Nuclease Free Water (Promega), and $2 \mu \mathrm{l}$ each of primer. The specimens were denatured first at $94^{\circ} \mathrm{C}$ for $30 \mathrm{~s}$, followed by annealing for 30 s at $58^{\circ} \mathrm{C}$ for TGF- $\beta 1$; $50^{\circ} \mathrm{C}$ for $30 \mathrm{~s}$ for $\operatorname{smad} 2 ; 50^{\circ} \mathrm{C}$ for $35 \mathrm{~s}$ for $\operatorname{smad} 3$; and $65^{\circ} \mathrm{C}$ for $30 \mathrm{~s}$ for GAPDH, and extension at $72^{\circ} \mathrm{C}$ for $40 \mathrm{~s}$ ( 25 cycles for TGF- $\beta 1,30$ cycles for $\operatorname{smad} 2, \operatorname{smad} 3$ and GAPDH). Reverse transcriptase (RT)-PCR-amplified products were analyzed by $1.5 \%$ agarose gel electrophoresis containing ethidium bromide. Results were photographed using the Tanon 2500 Gel Imaging System (Tanon Science \& Technology Co., Ltd., Shanghai, China). Band intensities were semi-quantified using Tanon Gel Image System 1D software (v4.1.2), and subsequently normalized by dividing the band gray value of the target gene by the intensity of its corresponding GAPDH. Primer sequences were synthesized by BGI Tech Solutions Co., Ltd., (Shenzhen, China) as follows: TGF- $\beta 1$ forward primer 5'-CGGCAGCTG TACATTGACTT-3' and reverse primer 5'-AGCGCACGATCA TGTTGGAC-3' (size 271 basepairs), smad2 forward primer 5'-ATGCCACGGTAGAAATGAC-3' and reverse primer 5'-TTGAGCAACGCACTGAAGG-3' (size 429 basepairs), smad3 forward primer 5'-ACCACGCAGAACGTGAACAC-3' 

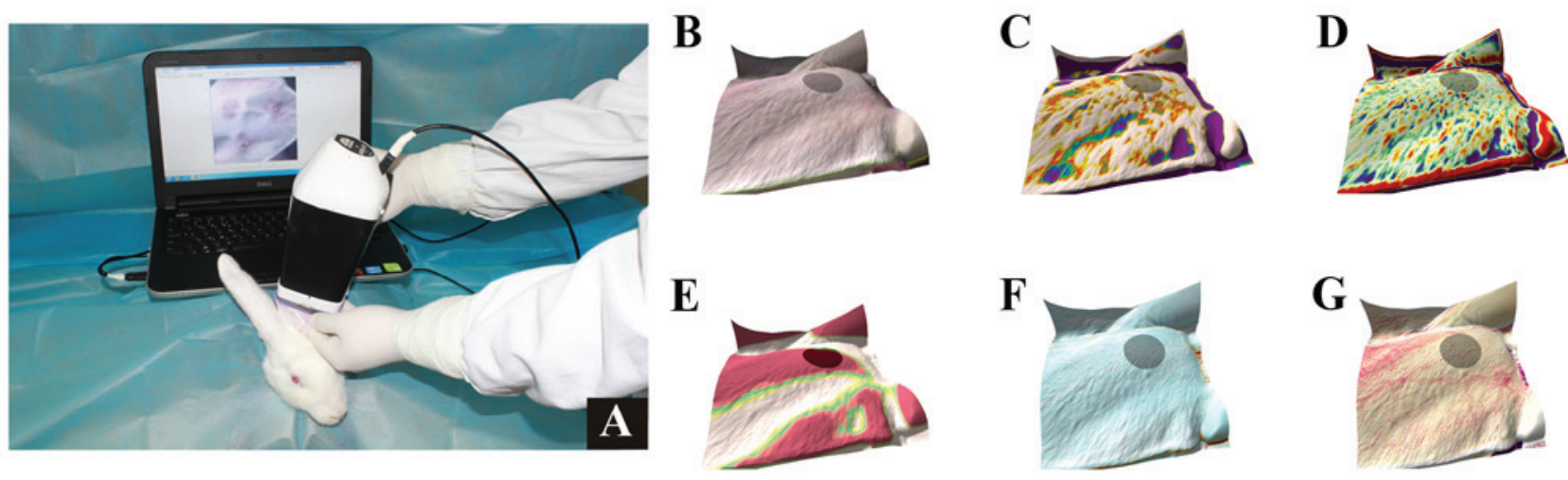

Figure 4. Assessment of scar characteristics using Antera $3 \mathrm{D}^{\circledast}$. (A) Photograph depicting the use of Antera $3 \mathrm{D}^{\circledR}$ for HS assessment. This system was used to capture 3D images of the (B) skin, (C) HS wrinkling, (D) skin texture, (E) areas with elevated volume, (F) melanin and (G) hemoglobin. HS, hypertrophic scar; 3D, Three-dimensional.

and reverse primer 5'-GCTGGTTTTCCTTGGGTACC-3' (size 419 basepairs), GAPDH forward primer 5'-GCGCCTGGTCAC CAGGGCTGCTT-3' and reverse primer 5'-TGCCGAAGTGGT CGTGGATGACCT-3' (size 464 basepairs).

Enzyme-linked immunosorbent assay (ELISA). The concentration of rabbit TGF- $\beta 1$, Smad2, Smad3, and Smad7 proteins in the HS tissue were determined using commercially available ELISA kits according to the manufacturer's instructions (R\&D Systems, Inc., Minneapolis, MN, USA).

Statistical analysis. Data from Antera $3 \mathrm{D}^{\circledR}$ were expressed as mean \pm standard deviation (SD); intergroup differences were assessed by paired t-testusing SPSS software ver 19.0(IBMCorp., NY, USA). Findings of RT-PCR and ELISA were expressed as mean \pm standard error of the mean (SEM); intergroup differences were assessed using Analysis Of Variance (ANOVA). A P-value $<0.05$ was considered indicative of a statistically significant difference.

\section{Results}

Antera $3 D^{\circledR}$ evaluation of $H S$. Prior to rESWT treatment, there were no statistically significant inter-group differences with respect to scar characteristics in the three study groups (data not provided). Until two weeks of rESWT treatment, no significant intergroup differences in terms of wrinkles and hemoglobin were observed between L-ESWT and S-ESWT groups $(\mathrm{P}=0.042$ and $\mathrm{P}=0.040$, respectively), between L-ESWT and H-ESWT $(\mathrm{P}=0.700$ and $\mathrm{P}=0.176$, respectively), or between H-ESWT and S-ESWT ( $\mathrm{P}=0.080$ and $\mathrm{P}=0.226$, repectively). However, three weeks later, wrinkles and hemoglobin in both L-ESWT and H-ESWT groups were significantly less than that in observed in the S-ESWT group (L-ESWT and S-ESWT, $\mathrm{P}=0.043$ and $\mathrm{P}=0.043$, respectively; H-ESWT and $\mathrm{S}-\mathrm{ESWT}, \mathrm{P}=0.037$ and $\mathrm{P}=0.025$, respectively). However, no significant difference was observed between L-ESWT and H-ESWT in this respect. Similar findings were observed till the fourth week (L-ESWT and S-ESWT, $\mathrm{P}=0.042$ and $\mathrm{P}=0.013$, respectively; H-ESWT and $\mathrm{S}$-ESWT, $\mathrm{P}=0.026$ and $\mathrm{P}=0.044$, respectively). Four weeks later, significant difference in the appearance of texture was observed between L-ESWT and S-ESWT ( $\mathrm{P}=0.014)$ groups. However, no such difference was observed between L-ESWT and H-ESWT, or between H-ESWT and S-ESWT groups. No significant differences were observed between the three study groups with respect to diameter, area, elevation of volume and melanin of HS.

Gene expression of TGF- $\beta 1 /$ Smad pathway. The effect of L-ESWT and H-ESWT on TGF- $\beta 1 /$ smad mRNA expression was assessed by RT-PCR, against that associated with use of GAPDH as an internal standard control. No significant difference in TGF- $\beta 1$ mRNA expression was found between the three groups. The smad 2 mRNA levels were significantly higher in H-ESWT as compared to that in the L-ESWT and S-ESWT groups $(\mathrm{P}=0.001$ and $\mathrm{P}=0.024$, respectively). No difference in smad 2 expression was observed between the L-ESWT and S-ESWT $(\mathrm{P}=0.476)$. The level of $\operatorname{smad} 3$ were found to be significantly decreased in L-ESWT as compared to that in H-ESWT and S-ESWT groups $(\mathrm{P}=0.000$ and $\mathrm{P}=0.047$, respectively). The smad 3 mRNA level in H-ESWT was significantly higher than that in the S-ESWT group $(\mathrm{P}=0.019)$ (Fig. 5).

Protein determination of TGF- $\beta 1 /$ Smad pathway. No significant differences in the concentrations of TGF- $\beta 1$, smad 2 and smad7 protein were observed in both L-ESWT and H-ESWT groups when compared to those in the S-ESWT group. The smad3 protein levels in the L-ESWT were significantly lower than those in the H-ESWT and S-ESWT groups $(\mathrm{P}=0.012$ and $\mathrm{P}=0.048$, respectively). No significant difference was observed between H-ESWT and S-ESWT groups with respect to smad3 concentration ( $\mathrm{P}=0.289)$ (Fig. 6).

\section{Discussion}

Treatment of HS is typically challenging due in part to the limited understanding of its pathogenesis. TGF- $\beta 1$ is known to stimulate synthesis of collagen and proteoglycan, which may promote HS formation via its influence on the metabolism of ECM (34). Fibroblasts isolated from HS tissue have been shown to have an increased expression of TGF- $\beta 1$ and TGF- $\beta R$ as compared to those from normal skin and are thought to play a vital role in HS formation, including the resultant increased synthesis of tissue inhibitor of matrix 
Comparison of TGF- $\beta 1$ mRNA

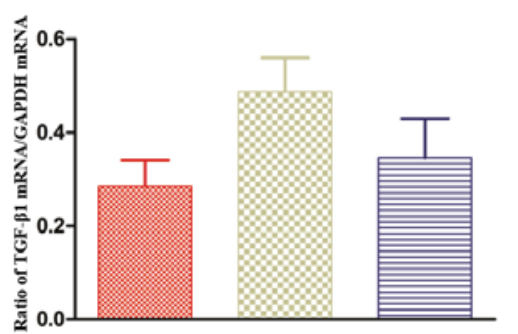

Comparison of Smad2 mRNA

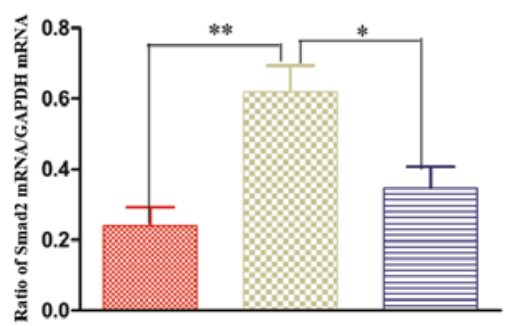

Comparison of Smad3 mRNA

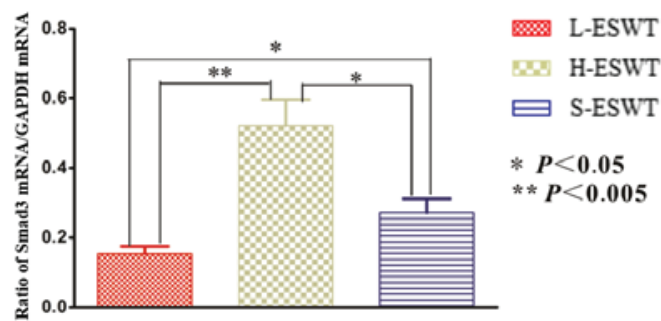

Figure 5. Results of reverse transcription-quantitative polymerase chain reaction analyzing the mRNA expression of TGF- $\beta 1$, Smad 2 and $S m a d 3$. ${ }^{*}<<0.05$ and ${ }^{* *} \mathrm{P}<0.005$, as indicated. TGF- $\beta 1$, transforming growth factor- $\beta 1$; ESWT, extracorporeal shock wave therapy; L-ESWT, lower-ESWT; H-ESWT, higher-ESWT; S-ESWT, sham-ESWT.

Comparison of TGF- $\beta 1$ concentration

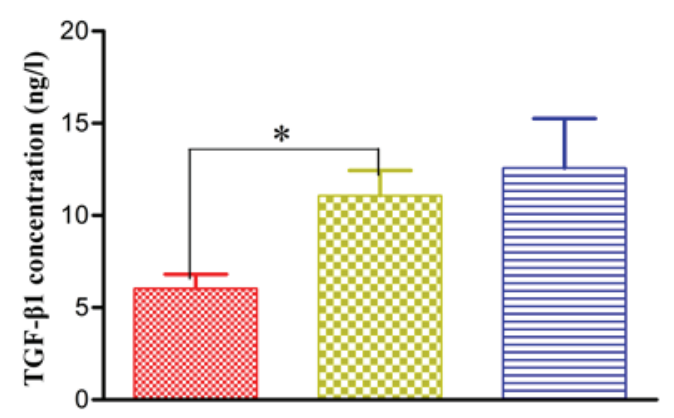

Comparison of Smad3 concentration

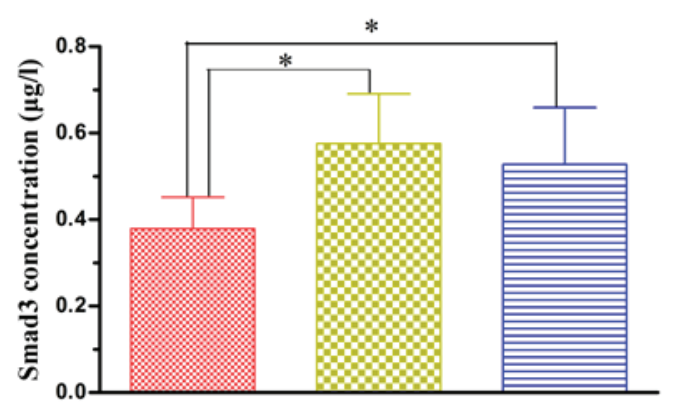

Comparison of Smad2 concentration

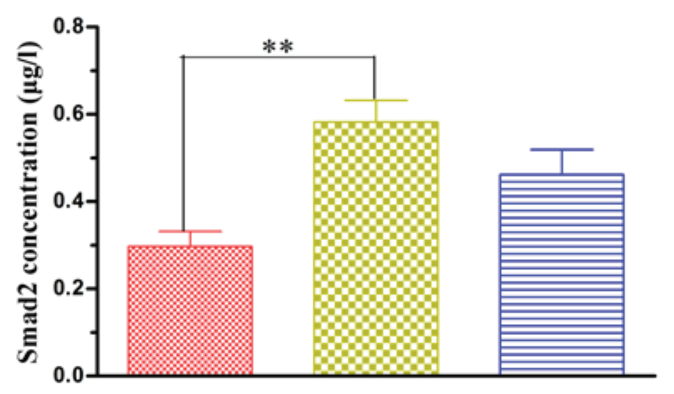

Comparison of Smad7 concentration

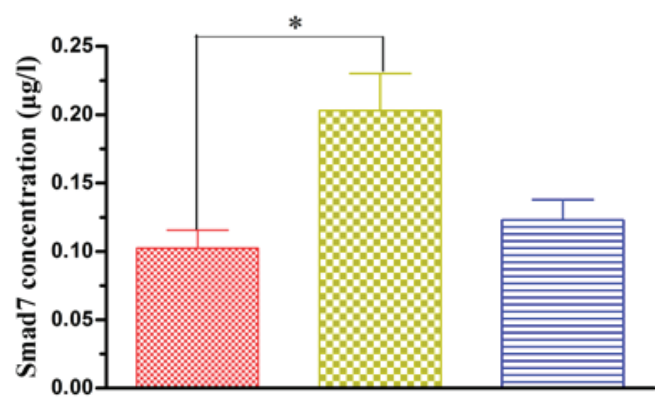

Figure 6. Results of ELISA for protein concentration of TGF- $\beta 1$, Smad2, Smad3 and Smad7. ${ }^{*} \mathrm{P}<0.05$ and ${ }^{* *} \mathrm{P}<0.005$, as indicated. TGF- $\beta 1$, transforming growth factor- $\beta 1$; ESWT, extracorporeal shock wave therapy; L-ESWT, lower-ESWT; H-ESWT, higher-ESWT; S-ESWT, sham-ESWT.

metalloproteinases, and which in turn decreases the activity of matrix metalloproteinases (35), resulting in excessive collagen synthesis and deposition (36). Further, TGF- $\beta 1$ was also shown to induce alpha-smooth muscle actin expression in myofibroblasts, conferring an increased ability for collagen synthesis and resistance to apoptotic inductors $(37,38)$. There are various receptors to which TGF- $\beta$ can bind to, the most important being two ligand-dependent complexes of heterodimeric transmembrane serine/threonine kinases, i.e., TGF- $\beta$ receptor I (TGF- $\beta$ RI) and TGF- $\beta$ receptor II (TGF- $\beta$ RII).

Among the various downstream signaling pathways mediated by TGF- $\beta 1$, the Smad pathway is thought to be of vital importance (6). Smad proteins respond to activated TGF- $\beta$ receptor complex and play an important role in the TGF- $\beta$ signal transduction from cell surface receptors to the nucleus. Smad family consists of at least eight subtypes of smad proteins, and these subtypes participate in various signal transduction pathways of various TGF- $\beta$ superfamily members.

Classically, smad proteins have been classified into three categories, namely, the receptor-regulated smads (R-Smads), common mediator smad (Co-Smad) and inhibitory smads (I-Smads) (39). R-Smads are amenable to activation after binding with TGF- $\beta$ RI to form a complex. R-Smads are classified into two categories depending on the activation by activin or TGF- $\beta$ (including smad 2 and smad3). In addition, smads are activated by bone morphogenetic proteins (including smadl, smad5 and smad8 (40-42), too.

Co-Smad consists of smad4 protein, which is involved in nearly all TGF- $\beta$ superfamily signal transduction pathways. I-Smads (including smad6 and smad7) are considered to be the 
negative feedback regulators, with the ability to bind to activated TGF- $\beta$ RI and block TGF- $\beta$ signal pathway (38). Smad6 mainly inhibits the bone morphogenetic protein pathway, while smad7 mainly blocks the TGF- $\beta$ signal pathway (43).

In normal tissues, TGF- $\beta$ isoforms exist in a precursor form, and combine with latent TGF- $\beta 1$ binding proteins to form a complex (44). Intracellular signaling of TGF- $\beta 1$ is initiated after latent TGF- $\beta 1$ binding proteins is dissociated from this complex (6). The activated TGF- $\beta 1$ is released and binds to TGF- $\beta$ RII, which in turn activates the TGF- $\beta$ RI. Activin-receptor-like kinase 5, one of the isoforms of TGF- $\beta$ RIs phosphorylates and activates $\operatorname{smad} 2$ and samd3; combine with smad4 and translocate into the nucleus to function as transcription factors, or participate in transcriptional control of certain genes.

The TGF- $\beta 1 /$ Smad pathway in HS tissue has been shown to manifestcertain typical characteristics. These include, increased expression and phosphorylation of samd 2 and/or samd3, but not smad7, during HS formation (39). Similar findings implicating TGF- $\beta 1$, smad 2 and smad 3 in HS formation have been reported by Chen et al (45). Therefore, blockage of the fibrotic processes mediated by TGF- $\beta 1 /$ smad signaling is a potential therapeutic target for prevention and treatment of HS (46-48). In this study, we treated HS in rabbit ear model with different EFD of ESWT and found no significant difference in the expression of TGF- $\beta 1$, smad2 and smad7. However, L-ESWT appeared to significantly inhibit smad3 expression.

Previous studies have shown that a reduction in smad3 expression may contribute to the reduction of collagen I synthesis and enhance wound healing which makes it a potential molecular target for treatment of HS $(45,49,50)$. In view of the important role of smad 3 in the TGF- $\beta 1 /$ smad signaling pathway, we speculate that this may be one of the mechanisms for the inhibitory effect of L-ESWT on HS formation. A comprehensive pre- and post-treatment of HS tissue could be invaluable in devising future therapeutic interventions.

Several instruments are currently available for assessment of HS, such as, patient and observer scar assessment scales, Vancouver scar scale and visual analog scale. However, these tools do not allow for an objective assessment of improvement of HS. Instead, a variety of techniques and instruments were used before and after treatment to detect the improvement of scar, for example, in a randomized controlled trial, Cho et al (10) documented the characteristics of scar in terms of thickness, melanin, erythema, transepidermal water loss, sebum, and elasticity with the help of different equipments such as ultrasonography, Mexameter ${ }^{\circledR}$, Tewameter $^{\circledR}$, Sebumeter $^{\circledR}$, and Cutometer ${ }^{\circledR}$, respectively. Although this method affords a comprehensive and accurate assessment of scar improvement, the requirement for multiple equipment and devices with varying operating requirements is a limitation.

Antera $3 \mathrm{D}^{\circledR}$ allows for acquisition of 3D images and 3D data which provides the basis for an objective quantification of the treatment efficacy and monitors changes over time. In the present study, we assessed the changes in wrinkles, texture, diameter, area, elevation of volume, melanin and hemoglobin of HS tissue in real-time using Antera 3D ${ }^{\circledR}$. This allowed for a comprehensive and objective assessment. Our study indicates that both L-ESWT and H-ESWT may improve the wrinkles and hemoglobin of HS. Only L-ESWT treatment was associated with a significant improvement in the texture of HS. However, there was no apparent influence of rESWT on the scar diameter, area and melanin content. This may be attributed to the lack of efficacy of ESWT treatment, or to the relatively short period of study. Future studies with a longer time frame are required to confirm our findings.

In addition to the relatively short-term period we have investigated in the present study, the other limitation of the study was the retrieval of 8 separate tissue biopsy samples under anesthesia over the course of 35 days post-treatment, which may have impacted on the gene and protein expression results.

Radial ESWT is a non-invasive, safe and well tolerated treatment modality for HS. In this study, L-ESWT treatment was associated with a significant improvement in wrinkles, hemoglobin and texture of HS. Downregulation of smad3 may be one of the mechanism of action of L-ESWT. Future studies are required to determine other potential mechanisms in order to further develop and improve efficacy of L-ESWT-based therapy in the clinical management of HS.

\section{References}

1. Gauglitz GG, Korting HC, Pavicic T, Ruzicka T and Jeschke MG: Hypertrophic scarring and keloids: Pathomechanisms and current and emerging treatment strategies. Mol Med 17: 113-125, 2011.

2. Niessen FB, Spauwen PH, Schalkwijk J and Kon M: On the nature of hypertrophic scars and keloids: A review. Plast Reconstr Surg 104: 1435-1458, 1999.

3. Hardy MA: The biology of scar formation. Phys Ther 69: 1014-1024, 1989.

4. Hayashida T, Decaestecker M and Schnaper HW: Cross-talk between ERK MAP kinase and Smad signaling pathways enhances TGF-beta-dependent responses in human mesangial cells. FASEB J 17: 1576-1578, 2003.

5. Asano Y, Ihn H, Yamane K, Jinnin M, Mimura Y and Tamaki K: Phosphatidylinositol 3-kinase is involved in alpha2(I) collagen gene expression in normal and scleroderma fibroblasts. J Immunol 172: 7123-7135, 2004.

6. Zhu Z, Ding J, Shankowsky HA and Tredget EE: The molecular mechanism of hypertrophic scar. J Cell Commun Signal 7: 239-252, 2013.

7. Klass BR, Grobbelaar AO and Rolfe KJ: Transforming growth factor beta1 signalling, wound healing and repair: A multifunctional cytokine with clinical implications for wound repair, a delicate balance. Postgrad Med J 85: 9-14, 2009.

8. Trisliana Perdanasari A, Torresetti M, Grassetti L, Nicoli F, Zhang YX, Dashti T, Di Benedetto G and Lazzeri D: Intralesional injection treatment of hypertrophic scars and keloids: A systematic review regarding outcomes. Burns Trauma 3: 14, 2015.

9. Steinstraesser L, Flak E, Witte B, Ring A, Tilkorn D, Hauser J, Langer S, Steinau HU and Al-Benna S: Pressure garment therapy alone and in combination with silicone for the prevention of hypertrophic scarring: Randomized controlled trial with intraindividual comparison. Plast Reconstr Surg 128: 306e-313e, 2011.

10. Cho YS, Jeon JH, Hong A, Yang HT, Yim H, Cho YS, Kim DH, Hur J, Kim JH, Chun W, et al: The effect of burn rehabilitation massage therapy on hypertrophic scar after burn: A randomized controlled trial. Burns 40: 1513-1520, 2014.

11. Azzam OA, Bassiouny DA, El-Hawary MS, El Maadawi ZM, Sobhi RM and El-Mesidy MS: Treatment of hypertrophic scars and keloids by fractional carbon dioxide laser: A clinical, histological, and immunohistochemical study. Laser Med Sci 31: 9-18, 2016.

12. O'Brien L and Jones DJ: Silicone gel sheeting for preventing and treating hypertrophic and keloid scars. Cochrane Database Syst Rev 9: CD003826, 2013.

13. Ogawa R, Miyashita T, Hyakusoku H, Akaishi S, Kuribayashi S and Tateno A: Postoperative radiation protocol for keloids and hypertrophic scars: Statistical analysis of 370 sites followed for over 18 months. Ann Plast Surg 59: 688-691, 2007. 
14. Zouboulis CC: Cryosurgery in dermatology. Hautarzt 66 834-848, 2015 (In German).

15. Zhang Q, Liu LN, Yong Q, Deng JC and Cao WG: Intralesional injection of adipose-derived stem cells reduces hypertrophic scarring in a rabbit ear model. Stem Cell Res Ther 6: 145, 2015.

16. Williams CC and De Groote S: Clinical inquiry: What treatment is best for hypertrophic scars and keloids? J Fam Pract 60 757-758, 2011.

17. Ledon JA, Savas J, Franca K, Chacon A and Nouri K: Intralesional treatment for keloids and hypertrophic scars: A review. Dermatol Surg 39: 1745-1757, 2013.

18. Macintyre L and Baird M: Pressure garments for use in the treatment of hypertrophic scars-a review of the problems associated with their use. Burns 32: 10-15, 2006.

19. Mustoe TA, Cooter RD, Gold MH, Hobbs FD, Ramelet AA, Shakespeare PG, Stella M, Téot L, Wood FM and Ziegler UE; International Advisory Panel on Scar Management: International clinical recommendations on scar management. Plast Reconstr Surg 110: 560-571, 2002.

20. Meaume S, Le Pillouer-Prost A, Richert B, Roseeuw D and Vadoud J: Management of scars: Updated practical guidelines and use of silicones. Eur J Dermatol 24: 435-443, 2014

21. Chaussy C, Brendel W and Schmiedt E: Extracorporeally induced destruction of kidney stones by shock waves. Lancet 2 : 1265-1268, 1980.

22. Rassweiler J, Rassweiler MC, Frede $T$ and Alken $P$ : Extracorporeal shock wave lithotripsy: An opinion on its future. Indian J Urol 30: 73-79, 2014.

23. Valchanou VD and Michailov P: High energy shock waves in the treatment of delayed and nonunion of fractures. Int Orthop 15: 181-184, 1991.

24. Maffulli G, Hemmings S and Maffulli N: Assessment of the effectiveness of extracorporeal shock wave therapy (ESWT) for soft tissue injuries (ASSERT): An online database protocol. Transl Med UniSa 10: 46-51, 2014.

25. Speed C: A systematic review of shockwave therapies in soft tissue conditions: Focusing on the evidence. Br J Sports Med 48 : $1538-1542,2014$

26. Goertz O, Lauer H, Hirsch T, Ring A, Lehnhardt M, Langer S Steinau HU and Hauser J: Extracorporeal shock waves improve angiogenesis after full thickness burn. Burns 38: 1010-1018, 2012

27. Dymarek R, Halski T, Ptaszkowski K, Slupska L, Rosinczuk J and Taradaj J: Extracorporeal shock wave therapy as an adjunct wound treatment: A systematic review of the literature. Ostomy Wound Manage 60: 26-39, 2014.

28. Zhao JC, Xian CJ, Yu JA and Shi K: Advancement in the research of effect of extracorporeal shock wave therapy on wound angiogenesis. Chin J Injury Repair Wound Healing 9: 80-84, 2014 (In Chinese).

29. Zhao J, Xue Y, Yu J, Shi K, Xian C and Zhou X: Advances in the research of mechanism of enhancement of wound healing with extracorporeal shock wave therapy. Zhonghua Shao Shang Za Zhi 31: 315-317, 2015 (In Chinese).

30. Fioramonti P, Cigna E, Onesti MG, Fino P, Fallico N and Scuderi N: Extracorporeal shock wave therapy for the management of burn scars. Dermatol Surg 38: 778-782, 2012.

31. Cho YS, Joo SY, Cui H, Cho SR, Yim H and Seo CH: Effect of extracorporeal shock wave therapy on scar pain in burn patients: A prospective, randomized, single-blind, placebo-controlled study. Medicine (Baltimore) 95: e4575, 2016.

32. Saggini R, Saggini A, Spagnoli AM,Dodaj I, CignaE, Maruccia M, Soda G, Bellomo RG and Scuderi N: Extracorporeal shock wave therapy: An emerging treatment modality for retracting scars of the hands. Ultrasound Med Biol 42: 185-195, 2016.

33. Morris DE, Wu L, Zhao LL, Bolton L, Roth SI, Ladin DA and Mustoe TA: Acute and chronic animal models for excessive dermal scarring: Quantitative studies. Plast Reconstr Surg 100: 674-681, 1997.

34. Köse $\mathrm{O}$ and Waseem A: Keloids and hypertrophic scars: Are they two different sides of the same coin? Dermatol Surg 34: 336-346, 2008.
35. Scott PG, Dodd CM, Tredget EE, Ghahary A and Rahemtulla F: Immunohistochemical localization of the proteoglycans decorin, biglycan and versican and transforming growth factor-beta in human post-burn hypertrophic and mature scars. Histopathology 26: 423-431, 1995.

36. Shah M, Foreman DM and Ferguson MW: Neutralisation of TGF-beta 1 and TGF-beta 2 or exogenous addition of TGF-beta 3 to cutaneous rat wounds reduces scarring. J Cell Sci 108: 985-1002, 1995.

37. Desmoulière A, Geinoz A, Gabbiani $F$ and Gabbiani G: Transforming growth factor-beta 1 induces alpha-smooth muscle actin expression in granulation tissue myofibroblasts and in quiescent and growing cultured fibroblasts. J Cell Biol 122: 103-111, 1993.

38. Moulin V, Larochelle S, Langlois C, Thibault I, Lopez-Vallé CA and Roy M: Normal skin wound and hypertrophic scar myofibroblasts have differential responses to apoptotic inductors. J Cell Physiol 198: 350-358, 2004.

39. Kopp J, Preis E, Said H, Hafemann B, Wickert L, Gressner AM, Pallua N and Dooley S: Abrogation of transforming growth factor-beta signaling by SMAD7 inhibits collagen gel contraction of human dermal fibroblasts. J Biol Chem 280: 21570-21576, 2005.

40. Xu J, Lamouille S and Derynck R: TGF-beta-induced epithelial to mesenchymal transition. Cell Res 19: 156-172, 2009.

41. Schmierer B and Hill CS: TGFbeta-SMAD signal transduction: Molecular specificity and functional flexibility. Nat Rev Mol Cell Biol 8: 970-982, 2007.

42. Massagué J: How cells read TGF-beta signals. Nat Rev Mol Cell Biol 1: 169-178, 2000.

43. Arno AI, Gauglitz GG, Barret JP and Jeschke MG: New molecular medicine-based scar management strategies. Burns 40: 539-551, 2014.

44. Annes JP, Munger JS and Rifkin DB: Making sense of latent TGFbeta activation. J Cell Sci 116: 217-224, 2003.

45. Chen W, Fu X, Sun T, Sun X, Zhao Z and Sheng Z: Change of gene expression of transforming growth factor-beta1, Smad 2 and Smad 3 in hypertrophic scars skins. Zhonghua Wai Ke Za Zhi 40: 17-19, 2002 (In Chinese)

46. Wu C, Jiang J, Boye A, Jiang Y and Yang Y: Compound Astragalus and Salvia miltiorrhiza extract suppresses rabbits' hypertrophic scar by modulating the TGF- $\beta /$ Smad signal. Dermatology 229: 363-368, 2014.

47. Bai X, He T, Liu J, Wang Y, Fan L, Tao K, Shi J, Tang C, $\mathrm{Su} \mathrm{L}$ and $\mathrm{Hu}$ D: Loureirin B inhibits fibroblast proliferation and extracellular matrix deposition in hypertrophic scar via TGF- $\beta$ /Smad pathway. Exp Dermatol 24: 355-360, 2015.

48. Wang X, Chu J, Wen CJ, Fu SB, Qian YL, Wo Y, Wang C and Wang DR: Functional characterization of TRAP1-like protein involved in modulating fibrotic processes mediated by TGF- $\beta /$ Smad signaling in hypertrophic scar fibroblasts. Exp Cell Res 332: 202-211, 2015 .

49. Schultze-Mosgau S, Blaese MA, Grabenbauer G, Wehrhan F, Kopp J, Amann K, Rodemann HP and Rödel F: Smad-3 and Smad-7 expression following anti-transforming growth factor beta 1 (TGFbeta1)-treatment in irradiated rat tissue. Radiother Oncol 70: 249-259, 2004.

50. Ashcroft GS, Yang X, Glick AB, Weinstein M, Letterio JL, Mizel DE, Anzano M, Greenwell-Wild T, Wahl SM, Deng C and Roberts AB: Mice lacking Smad3 show accelerated wound healing and an impaired local inflammatory response. Nat Cell Biol 1: 260-266, 1999.

This work is licensed under a Creative Commons Attribution-NonCommercial-NoDerivatives 4.0 International (CC BY-NC-ND 4.0) License. 